\title{
The Statistical Analysis Techniques to Support the NGNP Fuel Performance Experiments
}

The INL is a

U.S. Department of Energy

National Laboratory

operated by

Battelle Energy Alliance

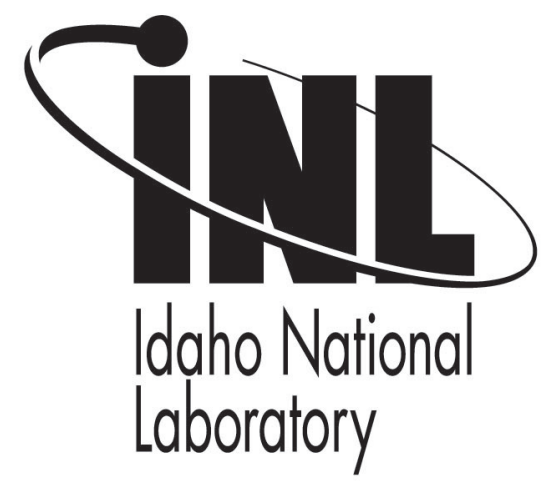

\section{Binh T. Pham} Jeffrey J. Einerson

\section{ANS Annual Meeting}

\author{
June 2010
}

This is a preprint of a paper intended for publication in a journal or proceedings. Since changes may be made before publication, this preprint should not be cited or reproduced without permission of the author. This document was prepared as an account of work sponsored by an agency of the United States Government. Neither the United States Government nor any agency thereof, or any of their employees, makes any warranty, expressed or implied, or assumes any legal liability or responsibility for any third party's use, or the results of such use, of any information, apparatus, product or process disclosed in this report, or represents that its use by such third party would not infringe privately owned rights. The views expressed in this paper are not necessarily those of the United States Government or the sponsoring agency. 


\title{
The Statistical Analysis Techniques to Support the NGNP Fuel Performance Experiments
}

\author{
Binh T. Pham ${ }^{1}$ and Jeffrey J. Einerson \\ Human Factor, Controls and Statistics Department \\ Nuclear Science and Technology \\ Idaho National Laboratory, Idaho Falls, ID 83415
}

\begin{abstract}
This paper describes the development and application of statistical analysis techniques to support the Advanced Gas Reactor (AGR) experimental program on Next Generation Nuclear Plant (NGNP) fuel performance. The experiments conducted in the Idaho National Laboratory's Advanced Test Reactor employ fuel compacts placed in a graphite cylinder shrouded by a steel capsule. The tests are instrumented with thermocouples embedded in graphite blocks and the target quantity (fuel/graphite temperature) is regulated by the $\mathrm{He}-\mathrm{Ne}$ gas mixture that fills the gap volume. Three techniques for statistical analysis, namely control charting, correlation analysis, and regression analysis, are implemented in the SAS-based NGNP Data Management and Analysis System (NDMAS) for automated processing and qualification of the AGR measured data. The NDMAS also stores daily neutronic (power) and thermal (heat transfer) code simulation results along with the measurement data, allowing for their combined use and comparative scrutiny. The ultimate objective of this work includes (a) a multi-faceted system for data monitoring and data accuracy testing, (b) identification of possible modes of diagnostics deterioration and changes in experimental conditions, (c) qualification of data for use in code validation, and (d) identification and use of data trends to support effective control of test conditions with respect to the test target. Analysis results and examples given in the paper show the three statistical analysis techniques providing a complementary capability to warn of thermocouple failures. It also suggests that the regression analysis models relating calculated fuel temperatures and thermocouple readings can enable online regulation of experimental parameters (i.e. gas mixture content), to effectively maintain the target quantity (fuel temperature) within a given range.
\end{abstract}

\footnotetext{
${ }^{1}$ Corresponding author. Phone: 208-526-8078,E-mail: Binh.Pham@inl.gov
} 


\section{INTRODUCTION}

Experimental data from the nuclear engineering field, particularly data on nuclear fuel are both hard to produce and challenging to interpret. The technical difficulties are rooted in (i) the experimental setup constrained by operating conditions of a test reactor core, (ii) limited diagnostics available for the test and (iii) rapid deterioration of instruments under the harsh irradiation and high temperature environment. At the same time, the value of experimental data cannot be overstated. Notably, design and licensing of advanced nuclear power plants require high-quality data from carefully planned and conducted experiments on one side, and development of modern tools for modeling and simulation of reactor processes on the other side. Within a science-based approach, these two aspects, experimentation and simulation, are strongly coupled, e.g., through effort in code validation and uncertainty quantification. As part of the Research and Development (R\&D) program on Next Generation Nuclear Plants (NGNP), it is envisioned that data, both experimental and computational, generated in the NGNP program are processed by state-of-the-art tools to ensure that the high-quality (and characteristically expensive) data remain accessible and usable by future generations of scientists and engineers in decades to come. This paves the way for the development of the NGNP Data Management and Analysis System (NDMAS) [1,2,3].

In this paper, we discuss statistical analysis methodologies and applications within NDMAS data qualification process to support nuclear fuel performance experiments. The relevant NDMAS functions are presented by example using data from the Advanced Gas Reactor (AGR) fuel performance tests within the NGNP Fuel Development and Qualification Program [4,5]. The AGR tests conducted in the Advanced Test Reactor (ATR) at the Idaho National Laboratory (INL) aim to obtain data on fuel behavior under normal and accident conditions of a new generation of Very-High-Temperature gas-cooled Reactors (VHTR).

In a nutshell, the AGR tests employ fuel compacts placed in a graphite cylinder shrouded by a steel capsule. Six capsules are used in the AGR-1 test. The tests are instrumented with thermocouples (TCs) embedded in graphite blocks and the target quantity (fuel/graphite temperature) is regulated by the He-Ne gas mixture that fills the gap volume [4,6]. The AGR-1 test was inserted in the ATR core in December 2006 and successfully completed in November 2009 resulting in fuel irradiation for a period of nearly three years. The AGR-1 data, including the thermocouple readings collected over the course of testing (2007-2009), were scrutinized and stored in NDMAS [7].

While no direct measurements of fuel temperature are available, the graphite temperature from TCs in AGR tests can be (and will be) used to evaluate the target quantities such as fuel temperature as well as to validate computer codes. Two groups of data generated during AGR irradiation are selected for this study. The first are measurement data including temperatures, gas flows, and pressures. For these data, qualification is not based on specification, but rather the answer to the question: are the data reflecting what is expected, or are anomalies or trends present that require investigation. Besides measured data, NDMAS also collects, qualifies and stores output from physics-based simulation codes, which calculate ATR neutronics (and subsequently, power) and thermal conditions of the AGR experiments [8,9].

The main data set in AGR-1 comes from TCs in the graphite blocks in six different capsules. Readings from each TC were recorded at least every five minutes during the irradiation period with an as-installed accuracy of $\pm 2 \%$ of reading. The standard TCs could not meet all experiment requirements, so commercial specialty TCs (with non-standard sheath or insulator materials) and INL fabricated Mo-Nb TCs with greater survival probability and least amount of drift were selected for the AGR experiments [4]. However, due to the harsh environment (high temperature and neutron fluence) nine out of eighteen TCs in the AGR-1 test failed in different times during the long irradiation (up to three years) period. The TC failures were examined by NGNP personnel in the data review committee (DRC) and it was concluded using input from thermal simulation results, that the TCs had either formed virtual junctions outside of the intended capsule or had developed another malfunction [7].

The TC failure has different manifestations, some are easy to recognize when the readings are clearly out of the expected measurement range or simply drop to zero (signal loss). Other malfunctions are harder to identify, for 
instance, when the thermocouple readings are still within the valid range, but have a certain bias (drift) or have formed a virtual junction somewhere in the test section or along the bundle cable. In fact, the virtual junction failure of two TCs in the AGR-1 test was discovered by a neon gas test at the beginning of the irradiation duration. This test varied neon fraction of the control gas mixture in one capsule at a time to see how TCs in other capsules responded to the gas composition change. The corresponding reading changes of TCs in other capsules indicate that a TC reads the temperature of another capsule instead of the intended capsule [4]. However, because of its complexity, this type of testing was conducted only once during the irradiation campaign. Thus, it is highly desirable to have other methods e.g., statistical analysis, for identification of such deceptive modes of instrument failure. Furthermore, some data from the deteriorated TCs may still be useful when the possible bias can be quantified and accounted for. The data trend of these TCs could still be used for test control or code validation. Early identification of all TC failure types is an important task in the entire fuel performance qualification campaign. Notably, toward the end of the AGR-1 test, three out of six capsules had all TCs failed, so their target fuel temperature control had to rely on functional TC readings from other capsules. That makes the need for accurate and timely estimation of temperatures in capsules containing all failed TCs even more important.

The objective of the present paper is to describe data qualification and experiment control capabilities enabled by statistical analysis methods selected and implemented in the NDMAS. The remainder of this paper is organized in four sections. Section 2 provides an overview of data qualification requirements and analysis tasks. Section 3 describes statistical analysis methods used in NDMAS for data accuracy monitoring. Section 4 discusses examples and lessons learned from the application of the NDMAS data qualification tools to the AGR-1 experimental data. Section 5 presents a new experiment control procedure to maintain the target fuel temperature by making use of the RA relationship between the simulated fuel temperatures and the TC readings. Section 6 provides a summary and concluding remarks and.

\section{DATA QUALIFICATION AND ANALYSIS IN NDMAS}

Data users and data generators determine the data that are needed for their application and the requirements the data must meet. In the NGNP Program, the data generated will be used to support the VHTR design and licensing and must therefore comply with NQA-1 quality assurance requirements [10]. Thus, all quality-affecting activities performed by the INL management and operation in the Very High Temperature Reactor (VHTR) Technology Development Office (TDO) follow the VHTR-TDO Quality Assurance Program Plan (QAPP) [11]. The quality-affecting activities for installing and conducting experiments in INL's Advanced Test Reactor (ATR) such as the AGR tests comply with the INL QAPP and specific ATR implementation procedures [12].

The NDMAS data qualification activity supports the VHTR QAPP goal as shown on the left of Figure 1. Namely, the independent review and testing of data accuracy by NDMAS verify that the data collected within an NQA-1 program have met the requirements for the designated planned data collection activity. At a minimum, qualified data in NDMAS are required to meet the following requirements [2]:

- Data must be correctly captured as being identical to the original data generated by the data collection programs.

- Data must be an accurate representation of the system or object being measured or modeled.

- Data must have been collected under an NQA-1 or equivalent approved QA program.

Data review and validation as elements of data qualification are the main focus of this paper. During the data review, data qualifiers or flags are applied to alert the end user to potential quality problems that may impact the usability of the data (e.g., requirements were not met). It is however noted that measurement uncertainty is not evaluated in a quantitative manner. This is why data review or validation is only a "first-step process" for the assessment of data usability. The full data usability assessment is more complex and multi-faceted than data review or validation, and as-a-rule requiring greater understanding of both underlying physical processes in the experiment and conditions of data usage. 


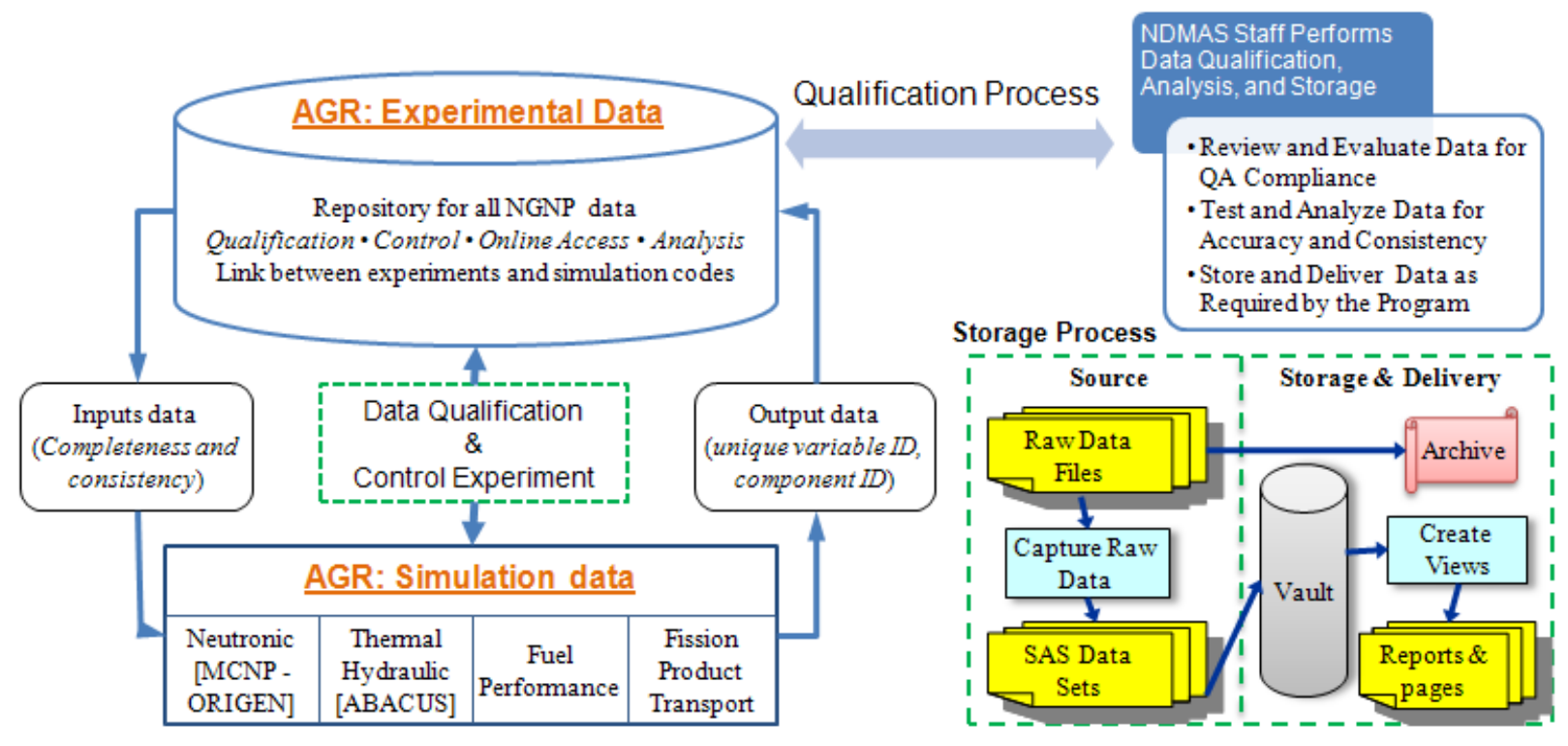

Figure 1: NDMAS data functionalities to support AGR experiments.

The review and testing of data can lead to one of three disposition states: qualified, trend, or failed. Qualified data meet all requirements. Trend data have minor bias but are still useful to the program. Failed data are deemed unusable because of gross failure in meeting the requirements. Records of testing and reviews are maintained in the NDMAS system to provide an auditable trail of data qualification. The qualification status of each data record in the system is identified to support the quality-cognizant and controlled use of the data. The present study expands beyond data qualification to include data analysis such as using data relationships for accuracy testing, early alert of instrument failure, and eventually enable the experiment control.

Conventional techniques used in data qualification, such as capture and range checks can be used to remove apparent and gross failures of the measuring instruments (e.g., thermocouples). However, data anomalies due to deteriorated instruments (e.g., drift or junction) are more subtle, requiring more sophisticated techniques to detect. Notably, variations in the AGR test data are caused not only by measurement device failures, but also by changes in the experimental conditions (both planned and unexpected). Statistical techniques (e.g., control charting, correlation analysis, and summary statistics) can be used to identify and flag the anomalies for further investigation. As a rule, decisions validating or invalidating suspect data and its reliability for further use requires application of both statistical and engineering concepts. For traceability, the resolution must then be documented in NDMAS, including identification, analysis, qualification decision, and its justification.

Statistical techniques used in data qualification range from calculation of simple statistics to more advanced modeling and analysis. The traditional analysis involves determining the statistics (e.g., population mean and standard variation) or the relationship (e.g., correlation and regression function) between random variables of interest using the past data (baseline or training period). These are then used to monitor the future data (monitoring period) and identify instances when measured data cross the established statistical bounds. Similar to the conventional techniques, the ultimate decision about a data anomaly is made by subject matter experts (e.g., the NGNP program DRC), which review all statistically identified out-of-bound events for possible scientifically defensible explanations in order to specify these data as qualified. Otherwise these data must be flagged as trend or failed. 


\section{STATISTICAL METHODS FOR DATA ACCURACY MONITORING}

The NDMAS primary data qualification functions include statistical analysis modules built on the SAS Enterprise Business Intelligence software [13]. To support data qualification for the AGR-1 test thermocouple measured data, three statistical analysis methods were selected and applied to provide early warning of TC failures. They are: (1) control charting (CC), (2) correlation analysis (CA), and (3) regression analysis (RA). These methods use different properties of TC data and their relationships specific to the AGR test (e.g., high correlation between $\mathrm{TCs}$ ) to identify different types of TC failures. Correlation analysis takes advantage of the fact that correlation between readings of within-capsule TC pairs is stronger than between inter-capsule pairs. This allows for the monitoring of changes in correlation statistics which is potentially useful in discerning TC virtual junction failure. Regression analysis uses the regression relationship between TCs and other relevant quantities to monitor for departure of future TC readings from regression predicted uncertainty bounds. This is potentially useful in identifying possible TC drift failure. Control charting uses a graphical display to visually monitor for departure from established statistical bounds. Therefore, the three methods (CC, CA and RA) provide a complementary capability in early warning of TC failure. The accuracy monitoring summary for TC readings is presented in Figure 2.

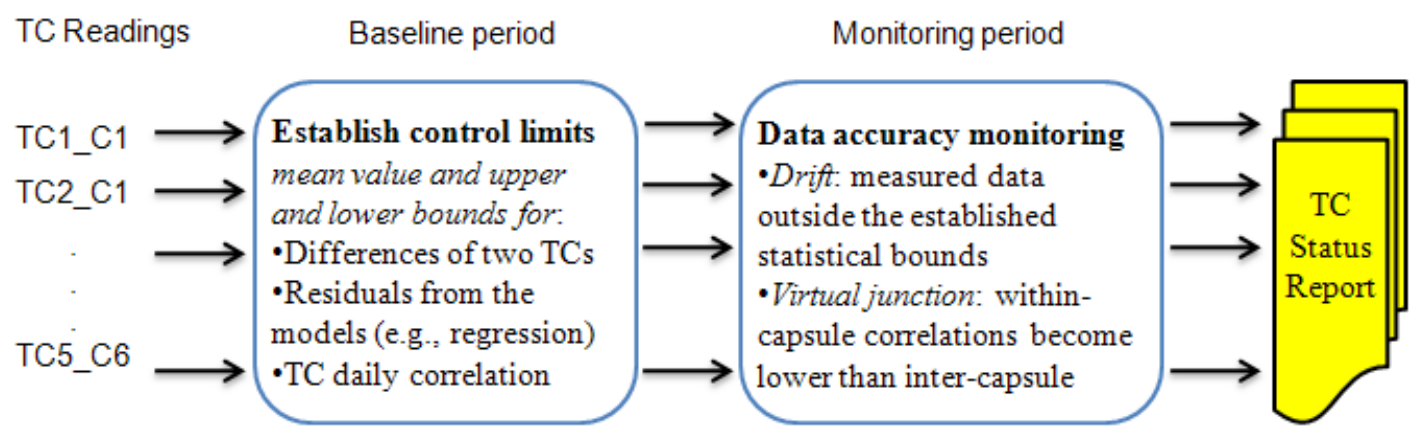

Figure 2: Thermocouple measured data accuracy monitoring in AGR experiment.

Early identification of data anomalies by the CC, CA and RA models will help timely collection of onsite information about the factors (which might otherwise be lost or forgotten) that later prove critical for modeling and code validation.

\subsection{Control Charting}

The control chart method deals with variation due to measurement uncertainty and hence requires that the control parameter be within a predefined range over time [14,15]. The purpose of control charting is to enable simple detection of events that are indicative of actual process change. This simplicity can be difficult to achieve, for example where the process characteristics are continuously varying. In such cases, the control chart is most useful in providing statistically objective criteria of change. If the process is "under control," all measurements will fall within the control limits. Any observation outside the limits, or systematic patterns within, suggest the introduction of a new (and likely unanticipated) source of variation, known as a special-cause variation. Thus a control chart "signaling" the presence of a special-cause requires immediate investigation. This makes the control limits very important and effective decision aids. The control limits provide information about process behavior and have no intrinsic relationship to any specification targets or engineering tolerance.

The control parameters can be different, e.g. TC readings, differences of two TCs, TC prediction residuals from various prediction models (physic-based models and regression models). Data ( $\mathrm{N}$ sample values) in a baseline 
period (a number of "past" cycles) are used to compute the population mean $(\mu)$ and standard deviation $(\sigma)$ of a controlled quantity $\left[T_{j}\right]$, assuming equal probability of sample values, expressed as follows $[16,17]$ :

$$
\mu=\frac{\sum_{j=1}^{N} T_{j}}{N} ; \quad \sigma=\sqrt{\frac{\sum_{j=1}^{N}\left(T_{j}-\mu\right)^{2}}{N-1}}
$$

Assuming a normal distribution of the control quantity, the upper and lower control limits that indicate the threshold at which the control parameter is considered statistically 'unlikely' due to common-causes (only $0.26 \%$ of the total measurements lies beyond $\pm 3 \sigma[15])$ are:

$$
L_{\text {upper }} / L_{\text {lower }}=\mu \pm 3 \sigma
$$

The control chart may have other optional upper and lower warning limits, typically two standard deviations above and below the mean value. The purpose in adding warning limits or subdividing the control chart into zones is to provide early notification if something is amiss.

The key component in the control chart methodology is the control chart rules. Rules provide basis to determine if some measured variable is out of control (outlier or trend versus consistent). The rules are based around the mean value and the standard deviation to maximize the failure warning performance (often dictated by problemspecific tolerance) and minimize false alarm (related to acceptable cost). Three sets of rules were applied for monitoring TC differences in AGR tests, namely:

- Out-of-control rule: the percentage limit out-of-control instances must reach when the out-of-control warning is raised (e.g., $10 \%$ ).

- Prolonged bias rule: significant percentage (e.g., 75\%) of data in monitoring period is more (or less) than the mean value indicating positive (or negative) bias.

- Trend rule: significant linear correlation (e.g., 0.8) in data time series indicates the presence of trend over time.

Figure 3 shows an example control chart for the differences between the TC2 and TC4 readings in capsule \#6 for AGR-1 test. The chart also includes the average TC differences for each ATR fuel cycle (gray line) to emphasize the data trend from cycle to cycle. The control chart is used to monitor for the following potential TC data problems:

Data shift: such a change may have various causes, e.g. introduction of new thermal mechanism in the capsule as a result of sudden change in the ATR operating parameters (e.g. control shim cylinder positions).

Data drift: A less conspicuous and therefore perhaps harder to diagnose than incidental errors or shifts, is a gradual change in accuracy or precision of the results. An upward or downward trend or drift of the mean or a gradual increase in the standard deviation may be too small to be revealed by short time monitoring periods but may be substantial over time. Such a drift could be discovered if a control chart were much longer, say several reactor cycles or use a "master" control chart with the mean values and standard deviations of the normal control charts (e.g., cycle means and standard deviations). Such a compressed control chart could be referred to as "Control Chart of the Trend" and is particularly suitable for a visual inspection of the trend. 


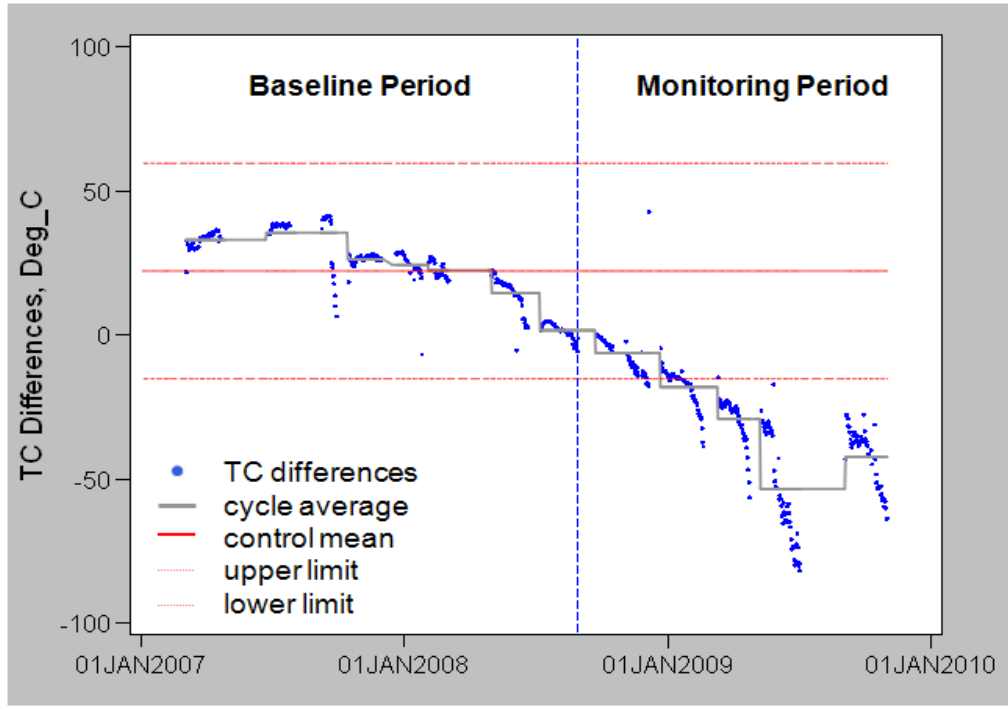

Figure 3: Control chart for differences between TC2 and TC4 in capsule \#6 of AGR-1 experiment.

\subsection{Correlation Analysis}

The correlation analysis (CA) method deals with daily correlation coefficients between readings of TC pairs, providing measures of the degree of association between variables [17], both within- and inter-capsules. The TCs in the AGR experiments read temperature every 5 minutes resulting in 288 measurements per TC per day. The pair correlation coefficient between two TCs is calculated using their readings during each day. The correlation coefficients of a TC pair from the same capsule are called within-capsule correlation and those of a TC pair from different capsules are called inter-capsule correlation. The formula for the correlation coefficient associated with simple linear regression between pairs of TC readings $\left[T_{1}, T_{2}\right]$ with the mean values $\left[\mu_{T_{1}}, \mu_{T_{2}}\right]$ is expressed as in the following [18]:

$$
r=\frac{\sum_{j=1}^{N}\left(T_{1, j}-\mu_{T_{1}}\right)\left(T_{2, j}-\mu_{T_{2}}\right)}{\sqrt{\sum_{j=1}^{N}\left(T_{1, j}-\mu_{T_{1}}\right)^{2}} \times \sqrt{\sum_{j=1}^{N}\left(T_{2, j}-\mu_{T_{2}}\right)^{2}}}
$$

where $N$ is the number of TC measurements per day (equal to 288 for most days).

The CA method was applied to identify possible deterioration of a TC. This occurs when the correlation between pairs of TCs in the same capsule decreases indicating possible drift and when the correlation between pairs of TCs in different capsules increases indicating a TC virtual junction or a singular (new) physics phenomenon (e.g. graphite crack near the TC location). The most challenging task in implementation of TC correlation analysis for data accuracy monitoring is finding a compact and comprehensive visual display for a large number of TC pairs (153 pairs are formed from 18 TCs in the AGR-1 test).

The box plots in Figures $4 \mathrm{a}$ and $4 \mathrm{~b}$ show that the summary statistics (e.g., population mean, median and variation) of the daily correlation coefficients as a function of the ATR fuel cycle could be an effective way to present the statistical trend in TC correlation over time. Typically, pairs of TCs within a capsule exhibit strong 
correlation, as shown in Figure 4a (e.g., TC2 and TC4 in capsule \#6). Those in different capsules exhibit weaker correlations as shown in Figure 4b (e.g., TC2 in capsule \#4 and TC2 in capsule \#6). This observed trend of daily TC correlations could be used for early warning indication of possible TC failure as follows:

- Between-capsule correlations of one TC consistently higher than within-capsule correlations indicate a potential virtual junction of that TC.

- Low within-capsule correlation indicates potential drift or failure of at least one of the TCs in the pair.

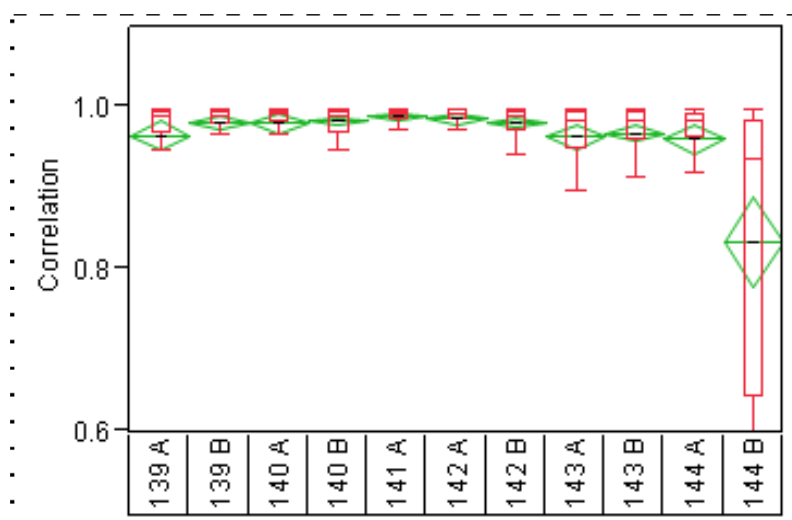

: Figure 4a: Cycle summary statistics for within- capsule daily correlation between TC2 and TC4 in capsule \#6.

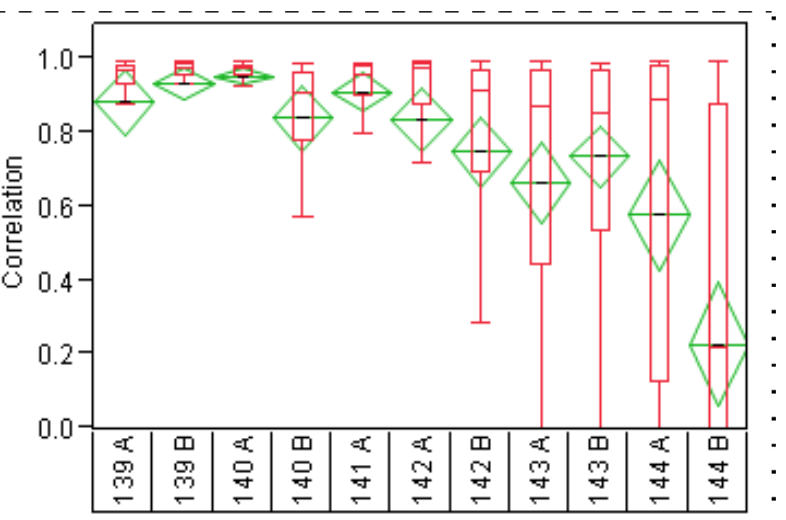

Figure 4b: Cycle summary statistics for inter- : capsule daily correlation between TC2 in capsule \#4 * and TC2 in capsule \#6.

\subsection{Regression Analysis}

Regression analysis (RA) refers to techniques for modeling and analysis of numerical data consisting of values of a dependent variable as a function of one or more independent variables (also known as predictors). The predicted dependent variable (e.g., time series readings $T_{N}(t)$ ) in multiple regression analysis is modeled as a function of $(\mathrm{p})$ independent variables (e.g., other TCs readings $T_{K}(t)$ where $\mathrm{K}=1,2 \ldots \mathrm{p}$ ). For example, by the most general type of linear regression [19]:

$$
T_{N}(t)=a_{O}+\sum_{K, K \neq N} a_{K} T_{K}(t)
$$

where $a_{O}, a_{K}$ are regression model estimates determined from best fitting of the predicted and measured data in the so-called training period. Typically, the estimation procedure is based on least squares, which makes use of the assumption about normally distributed random variation of the observation errors. The regression predictions of TCs in capsules \#4 \#5, and \#6 as a linear function of all remaining working TCs are presented by the dotted lines in Figure 5 . 


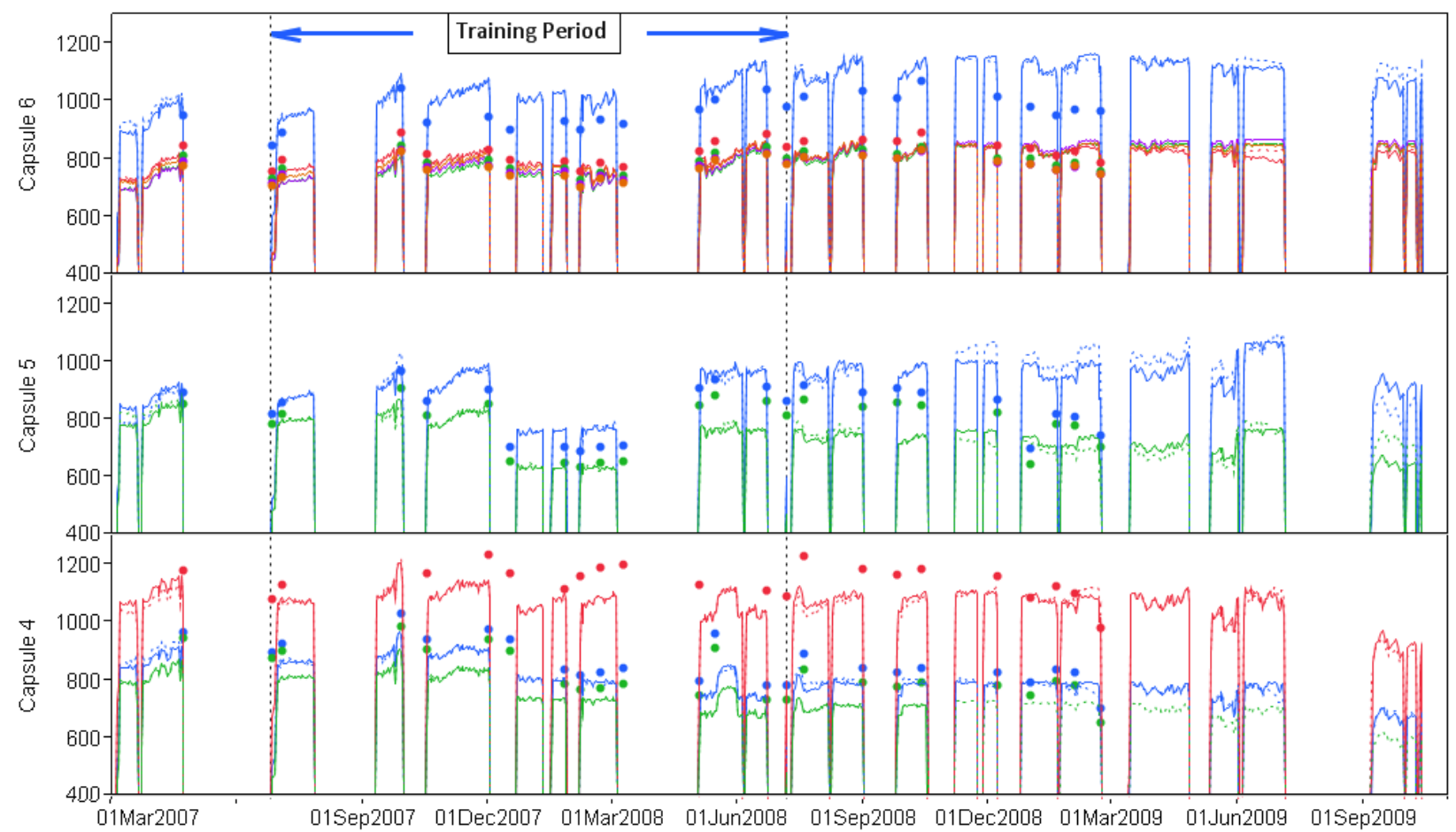

Figure 5: Linear regression projection of TC measurements (dotted line) were plotted together with measured temperatures (continuous lines). The blue color is for TC 1 , the red is for TC 2 , the green is for TC 3 , and the purple is for TC 4 .

The RA method is based on the assumption that a linear physical mechanism (linear heat conduction) governs temperature changes in the graphite block (hence readings of all TCs in the block), therefore the linear regression relationship (see example in eq. 4) established between time series TC readings in a training period will also persist in the monitoring period. The tight correlation between readings of TCs from both the same and different capsules in the AGR test leads to high prediction accuracy of the regression function. This is shown in Figure 5 by the close match between the measured and predicted values for all TCs even outside the training period. The regression functions for all TCs are highly statistically significant (significance level $p<0.001$ [15]) and have high coefficients of determination $\left(\mathrm{R}^{2} \sim 0.99\right)$. Furthermore, the regression procedure in SAS Enterprise Guide software (EGuide) provides not only estimates of the regression function $a_{K}$ and predicted subject TC temperatures but also the lower and upper limits (or bounds) with given confidence intervals (e.g., $95 \%$ or $99 \%$ [20]). These prediction bounds could be used to monitor future TC measurements for early drift warning.

\section{AGR-1 EXPERIMENTAL DATA ANALYSIS: IMPLEMENTATION AND LESSONS LEARNED}

The automated data accuracy monitoring for TC readings in the AGR-1 test implements the three statistical methods described in Section 3. For this purpose, we use SAS Enterprise Business Intelligence Software within the NDMAS system. The automation process is accomplished by the process flow in the SAS EGuide software package. This process flow provides the link between the implementation codes and data files in the SAS data base, which are updated regularly as the experiment progresses. The implementation codes calculate all necessary parameters and deliver the final results in web pages with html format. These web pages are displayed via the SAS Information 
Delivery Portal as shown in Figure 6 allowing remote data monitoring not only by the NDMAS personnel, but also by interested parties. The web pages are automatically updated with new test data by running the process flow in the SAS EGuide. In the same webpage, multiple graphs representing the results of the three statistical methods are displayed together for easy monitoring and interpretation of the results. The warning rules are implemented in NDMAS to automatically generate the TC status report when the failure warning level is reached.

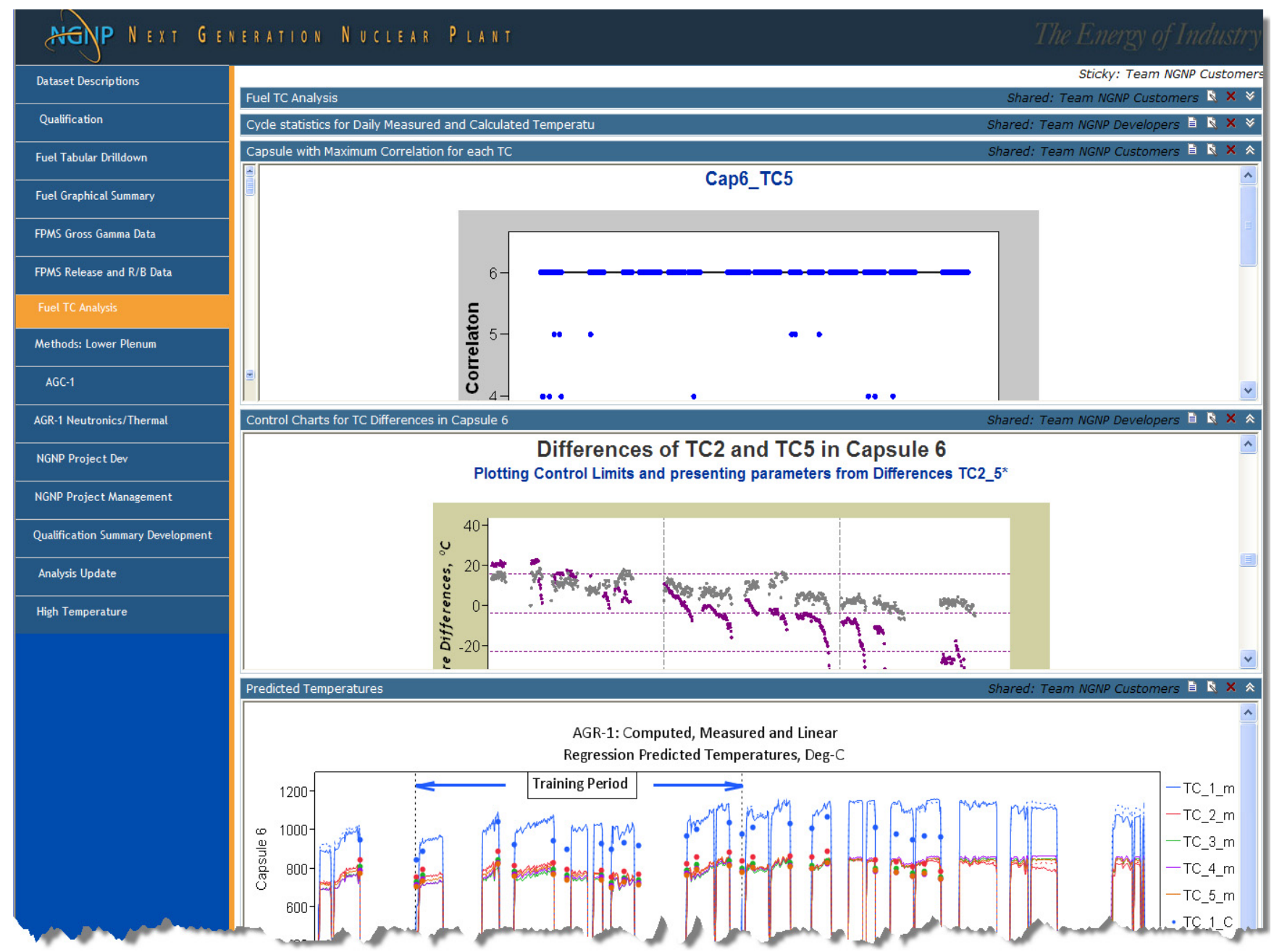

Figure 6: Online data monitoring uses the SAS Information Delivery Portal

To test the process developed, the statistical analysis methods (CC, CA, RA) are applied in AGR-1 test for accuracy monitoring of all TC readings to provide early warning of potential TC failure. In what follows, we discuss examples of identifications of TC failure instances. Table 1 summarizes the statistical method performance in early warning detection of TC failure for the AGR-1 experiment. Both failures known to the NGNP Program (by other methods such as by comparing with ABACUS simulation results or the neon gas test for virtual junction) and new TC failures are analyzed to evaluate the performance of the statistical methods. We will also discuss lessons learned in implementing statistical methods for AGR-1 TC data qualification. 
Table 1: NDMAS statistical analysis method performance in detecting early warning signs of TC failures in the AGR-1 experiment.

\begin{tabular}{|c|c|c|c|}
\hline & $\begin{array}{l}\text { AGR-1 parameters of } \\
\text { interest }\end{array}$ & Identified TC failures & Generic limitation \\
\hline $\begin{array}{l}\text { Control } \\
\text { Charting }\end{array}$ & $\begin{array}{l}\text { Differences of functional } \\
\text { TC readings for } 3 \text { capsules }\end{array}$ & $\begin{array}{l}\text { Drift down of TC } 1 \& 2 \text { in } \\
\text { capsule } \# 6 \text { during last cycles. }\end{array}$ & \multirow{4}{*}{$\begin{array}{l}\text { All statistical methods assume } \\
\text { accurate measured data in the } \\
\text { baseline period to establish } \\
\text { proper control statistics or } \\
\text { relationship models, which are } \\
\text { essential to the accurate } \\
\text { conclusions. }\end{array}$} \\
\hline $\begin{array}{l}\text { Correlation } \\
\text { Analysis }\end{array}$ & $\begin{array}{l}\text { Daily correlation of } 153 \\
\text { TC pairs }\end{array}$ & $\begin{array}{l}\text { Virtual junction failure of TC1 in } \\
\text { capsules } \# 1 \& \# 2 \text {. }\end{array}$ & \\
\hline $\begin{array}{l}\text { Regression } \\
\text { Analysis }\end{array}$ & Functional TC readings & $\begin{array}{l}\text { Drift down failure of TC3 in } \\
\text { capsule } \# 3 \text { and TC2 in capsule } \# 6 .\end{array}$ & \\
\hline $\begin{array}{l}\text { Combination } \\
\text { of Methods }\end{array}$ & Functional TC readings & Drift down of TC2 in capsule $\# 6$. & \\
\hline
\end{tabular}

\subsection{Correlation analysis for early warning of TC virtual junction}

This section describes a successful application of the correlation analysis (CA) method in identifying a "virtual junction" of TCs (failed TC wire formed a junction with another capsule) when the data suddenly showed an unexpected and persistent correlation between subject TC readings and TC readings in a different capsule. The AGR-1 test has 18 TCs in 6 capsules. There are 17 TC pairs for each subject TC including 1 (for capsule \#1 with two TCs) to 4 (for capsule \#6 with five TCs) within-capsule pairs and the rest are inter-capsule pairs (16 pairs for capsule \#1 and 13 pairs for capsule \#6). As stated earlier, the most challenging task in this correlation analysis is the creation of the comprehensive display of all pair correlations allowing for clear failure conclusion when the displaying quantities depart from the initial established property. For example, Figures $5 \mathrm{a}$ and $5 \mathrm{~b}$ above showing cycle statistics (mean and variation) are useful for monitoring TC drift when the within-capsule correlations decrease. The other display technique discussed below is used for TC virtual junction detection.

In order to clearly show when within-capsule correlations drop below inter-capsule correlations and indicate possible TC virtual junction, the capsule containing the TC having the maximum correlation with the subject TC is identified and recorded for all full power days for each subject TC. The blue dots in Figures 7a and 7b correspond to the number of the capsule containing the TC that is most highly correlated with the subject TC for each full power day. The black line represents the number of the capsule containing the subject TC. Therefore, the concentration of the blue dots on the black line means that the subject TC is most highly correlated with another TC in the same capsule. This is shown in Figure 7a for TC5 in capsule \#6. On the contrary, the blue dots in figure 7b for subject TC1 in capsule \#2 are concentrated on the horizontal line corresponding to capsule \#6 instead of the black line corresponding to capsule $\# 2$. This shows that the readings of this subject TC are most highly correlated with the readings of some TC in capsule \#6. This fact is consistent with the confirmed instance of TC1 in capsule \#2 being in virtual junction somewhere in capsule \#6 which was originally identified by the neon gas test at the beginning of the AGR-1 test campaign.

The same technique of correlation analysis for identification of virtual junctions was applied to all TCs in the AGR-1 test. Two known such failure instances were confirmed. The confirmed cases sufficiently demonstrate that the technique of calculating and displaying TC correlations can be very useful and effective as a means to monitor TC readings for virtual junction warning. 


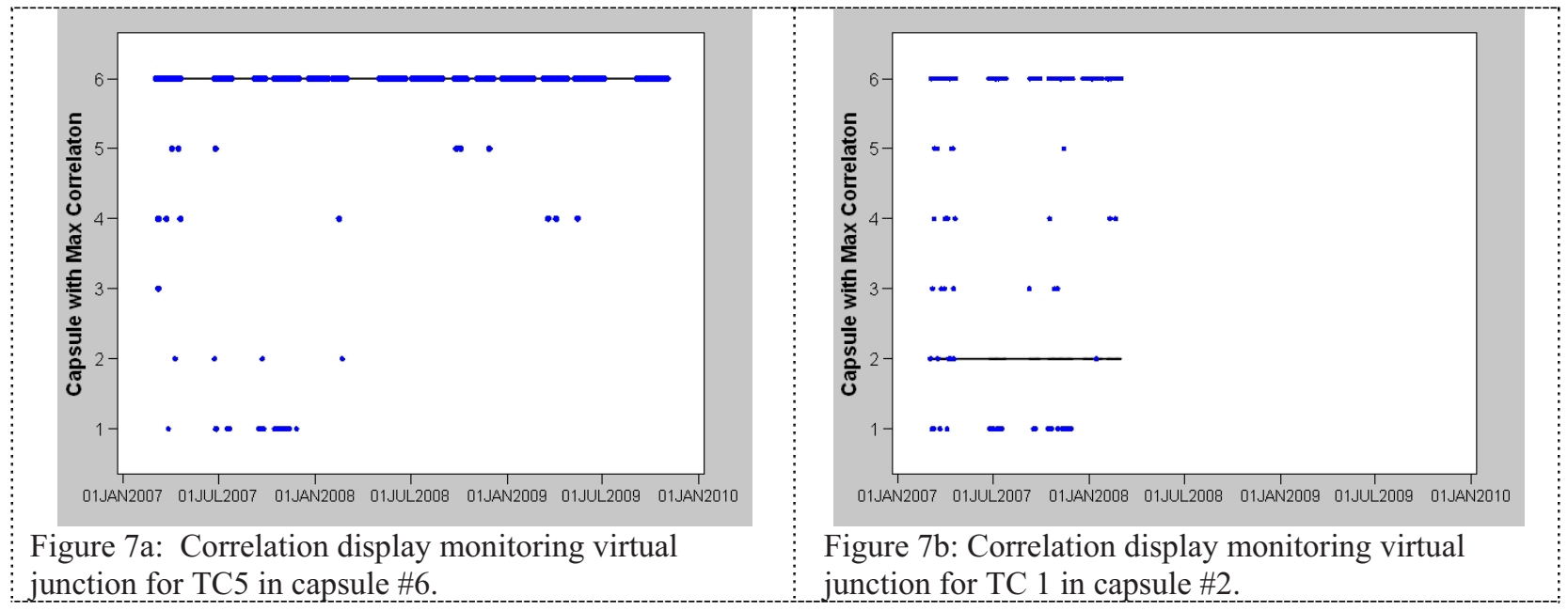

\subsection{Regression analysis for early warning of TC drifting}

The RA method was applied to the data set from AGR-1 and found to be effective in identifying "subtle" outliers i.e., when the TC readings in the monitoring period cross a $99 \%$ prediction limit. However, these outliers are not only due to possible deterioration of the TCs, but also due to unexpected variations in experimental conditions (e.g. gas mixture, core power) or drastic changes in the fuel/graphite conditions (e.g., boron depletion, burnup, graphite properties change due to exposure to fast neutron fluence). This, in turn, might change the regression relationship in the monitoring period. The analysis also suggests that the data trending capability of the RA models can enable fill-in of the missing readings of failed TCs allowing immediate online regulation of experimental parameters (e.g. gas mixture content) to control the target quantity (i.e. evaluated fuel temperature) within a given range in those capsules, which have all TCs failed. Furthermore, early identification of data outliers by the RA model will help timely collection of onsite information about the factors causing the relationship change.

This subsection emphasizes the use of predicted TC readings together with their uncertainly limits to monitor for TC drift. Figure 8 presents an example of how regression modeling can identify the downward drift of TC1 in capsule \#3 after May $1^{\text {st }}, 2008$. The regression analysis uses all 9 functional TCs in capsules \#4, \#5, and \#6 as independent variables (or predictors) to estimate linear regression coefficients $\mathrm{a}_{\mathrm{i}}$ (in eq. 4) of the model for TC1 in capsule \#3. The SAS linear regression procedure uses all data prior to January $26^{\text {th }}, 2008$ as training data for model estimation, then predicts the TC1 readings in capsule \#3 together with upper and lower limits at a given confidence interval. The model's large coefficient of determination $\left(\mathrm{R}^{2}=0.9914\right.$, a measure of model precision [Draper et. al, 1981]) and low root mean square error ( $\mathrm{RMSE}=8.94{ }^{\circ} \mathrm{C}$ or about $1 \%$ of the $\mathrm{TC}$ readings) in the training period demonstrate the excellent fit of the model in the training period. The closeness of the measured (blue line) and predicted (red line) in Figure 8 also confirms that conclusion. Besides the model's good fit in the training period, the subject TC's qualified data (the continuous blue line) in the monitoring period are also close to the predicted value and lie well within the gray lines representing the upper and lower 99\% limits (or bounds). Figure 8 also includes the measured data in the monitoring period that were disqualified by the DRC due to the fact that they were in excess of $200{ }^{\circ} \mathrm{C}$ different than the thermal simulation value. This downward drift is confirmed by regression as shown by the dotted blue line being well below the model lower limit. This example provides confidence that the regression-based technique can help monitor and provide early warning for TC drift. 


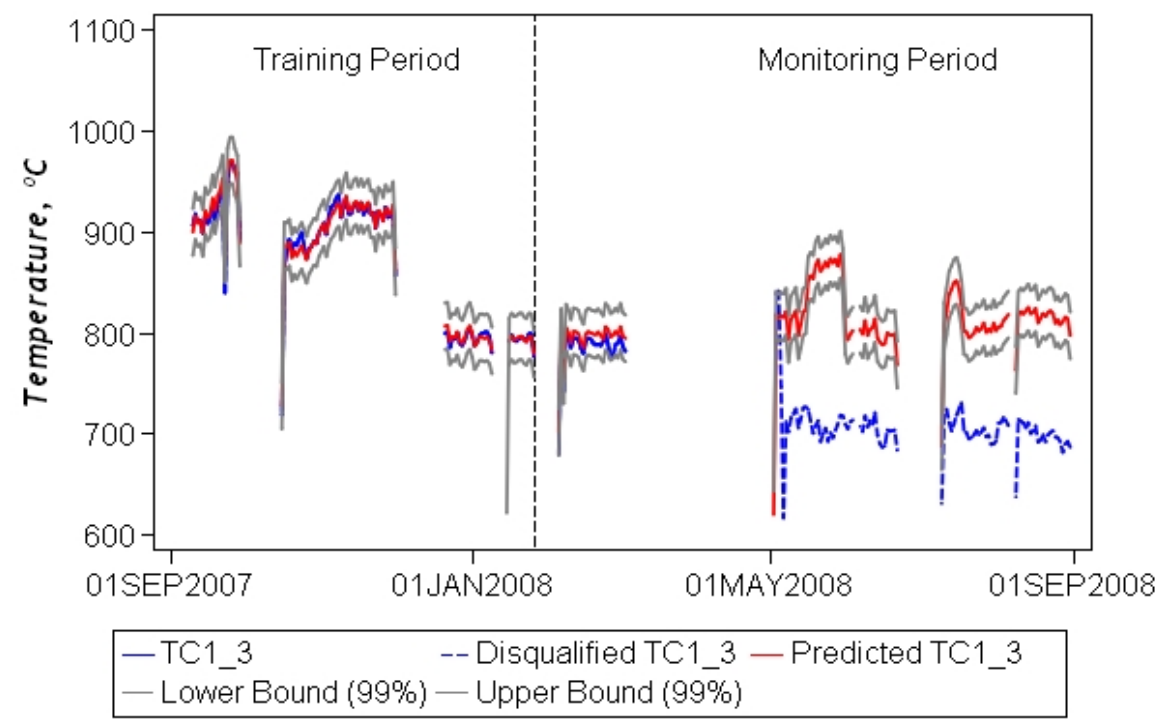

Figure 8: Regression-based predicted data (red line) with 99\% bounds (gray lines) and the TC measured data (blue lines) of TC 1 in capsule \#3.

\subsection{Combination of three statistical methods for early warning of TC failure}

The preceding examples apply three statistical analysis methods, CC, CA and RA, separately from each other, in monitoring and detecting certain types of TC failures. The following example shows that combining the failure indications of all three methods will increase confidence in the warning status and might offer hints to the possible cause of the failure. Figure 9 shows the TC2 readings are clearly lower than readings of the other TCs (TC3, TC4, and TC5) toward the end of the irradiation period even through all these four TCs are located near the edge of the graphite holder and at the same depth of 0.5 inch from the top and should be measuring approximately the same temperature. This possible downward drift of TC2 is consistently warned by all three statistical methods.

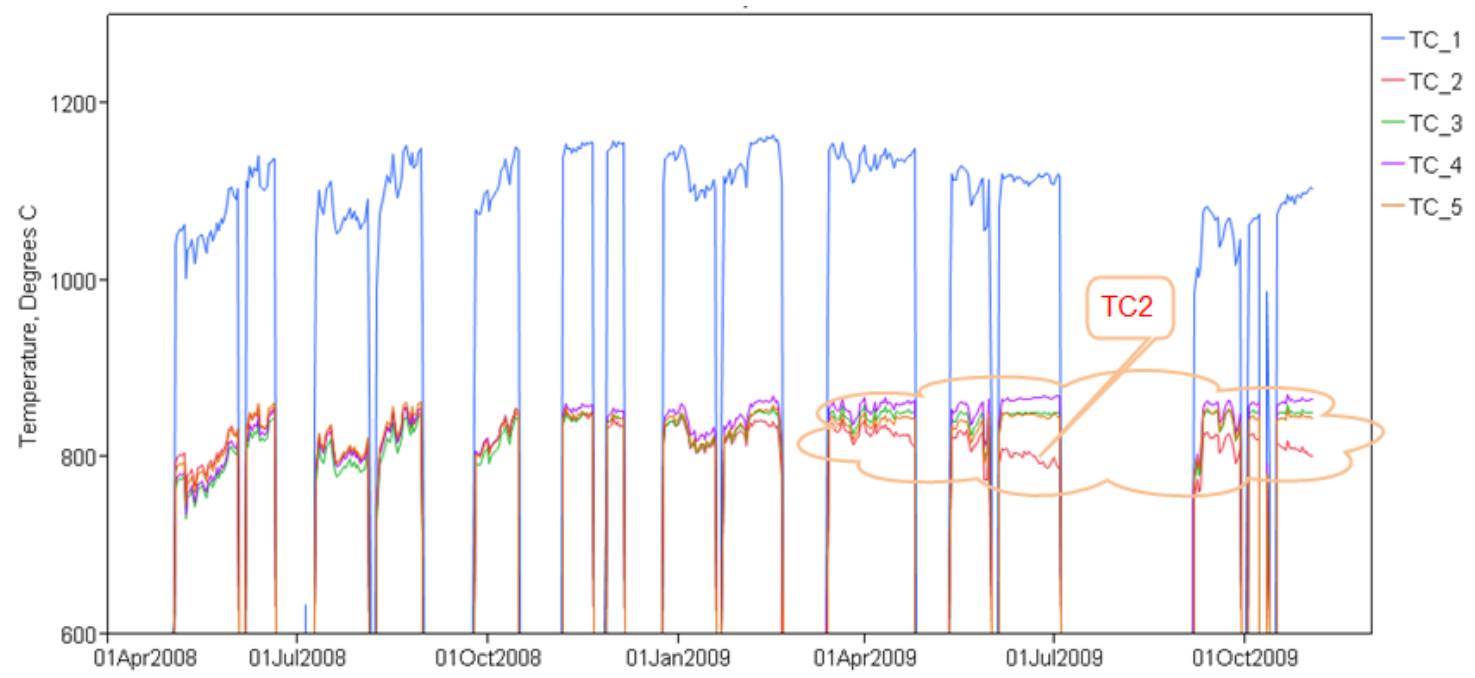

Fig.ure 9: Plots of all TC readings in capsule \#6 during the second half of the AGR-1 test. 
Starting with the regression analysis, the TC2 predicted temperatures (the red line on the top graph in figure 10) are higher than measured temperatures (blue line in the same graph) toward the end of the irradiation period indicating potential drift. The linear regression model of eight functional TCs was established based on the data before July 1, 2008. This regression-based downward drift finding is confirmed by the decrease of within-capsule correlation (TC2 and TC5 in capsule \#6) during the same later cycles as illustrated in the correlation statistic monitoring graph on the bottom left in Figure 10. The TC2 downward drift failure becomes even more certain, when the control chart monitoring display (bottom right of Figure 10) shows a departure from within the control limits for the TC2 and TC5 differences.

The credibility of the drift warning increases with more supporting and discriminating evidence. Figure 9 above shows the drop of TC2 readings while all other TCs in capsule \#6 readings increase confirms the early warning indications of all three statistical methods. The fact that the abnormal findings by the three statistical methods are only for the TC2 readings, suggests the downward drift is more likely because of TC2 deterioration.

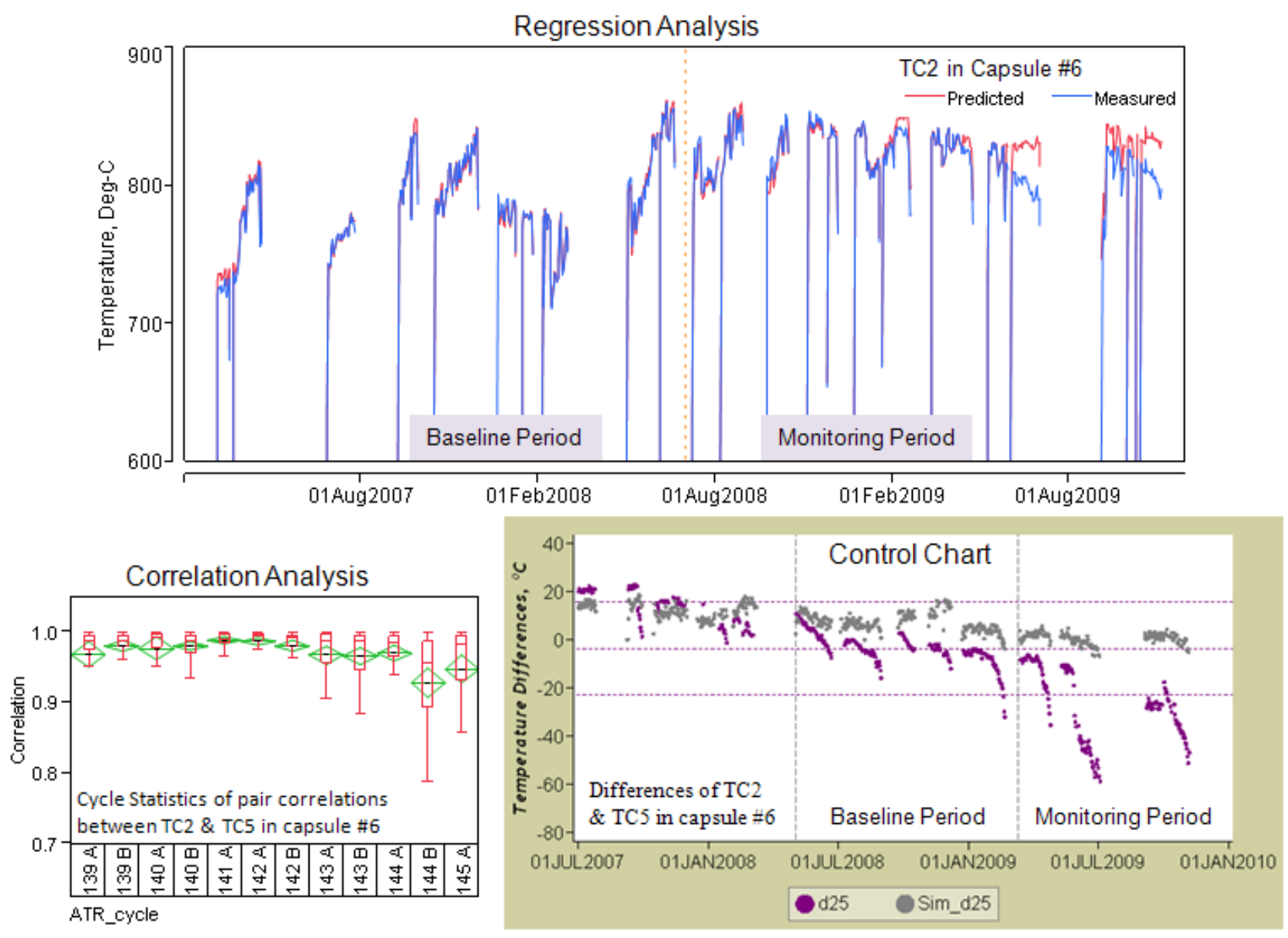

Figure 10: Combination of three statistical analysis methods increases confidence in early warning of the thermocouple reading drift for TC 2 in AGR-1 capsule \#6. 


\section{AGR EXPERIMENT CONTROL}

In general, experimental data from nuclear reactor design and safety are highly heterogeneous in their nature. This notion applies fully to nuclear fuel performance experiments. The AGR experimental data include local (measurement) and transient (measurement, simulation) data, integral (fission product release monitoring data from the fission product monitoring system (FPMS)) and accumulative (post-irradiation examination (PIE)) data. The different data types are, however, highly correlated as they reflect the same underlying physical process. This observation has led the authors to suggest using the strong correlation between experimental and simulation data to enable uncertainty reduction for both experimental and simulation data streams: the simulation data can aid the accuracy testing in measurement data qualification and the experimental data is used for simulation code validation. Beyond the thermocouple measurements as the main data source in AGR, the accumulative data e.g. from PIE would helps to assess the accuracy of assumptions made in the ABACUS thermal model of the AGR capsules (e.g., the amount of graphite holder and fuel compact shrinkage under neutron irradiation or the neutron and heat induced component deformations leading to uneven regulation-gas gap). Furthermore, the combination of both experimental and simulation data creates an opportunity to control the experiments, i.e. sustaining the desired simulated quantities (e.g., evaluated fuel temperature), by using their established relationship with measurements (e.g., control TC temperature).

As noted early in this paper, the AGR-1 test involved several capsules, each comprised of fuel compacts under testing. The thermal conditions in the test section are monitored by thermocouples whose readings are exhibited on the Distributed Control System (DCS) [6]. The target fuel temperatures are defined in the AGR test plan $[4,5]$. The fuel compact temperatures are important both for characterization of the test conditions needed for validation of future fuel performance simulation codes, and for qualification of fuel performance in support of VHTR licensing. Success of the experiment campaign depends on whether the target fuel temperatures are stably maintained during the entire irradiation period. During the test operation, a gas gap between each capsule and the contained specimens receives a continuous supply of blended gas, namely helium and neon, which have vastly different thermal conductivities. As a minimum, gas blenders shall be capable of providing control blends in the range of $98 \%$ helium to $98 \%$ neon. Using readings from the control thermocouples in the test train, the gas mixture is adjusted to maintain the temperature in that capsule within $5^{\circ} \mathrm{C}\left(10^{\circ} \mathrm{F}\right)$ of the indicated temperature with reactor power at steady state $( \pm 2 \%)$. To this effect, the gas supply system must be able to adjust the gas mixture content at a frequency greater than the transportation time to the capsule [6]. The blending operations are performed in a mass flow controller (MFC) cabinet linked to a computer control console in the Loop Operation Control System (LOCS) area. The Irradiation Test Vehicle (ITV) gas control system monitors the gas supply manifold lineup and status. Each new bottle added to the supply manifold is automatically tested for moisture and gas composition to ensure the correct gas has been inserted in the correct position. All gas bottles, except for helium-3 (used in abnormal case of high power in ATR core), are tested and placed on- and off-line automatically and flow to each capsule shall be controlled such that total flow (helium plus neon) is less than $50 \mathrm{sccm}$.

The input required for the capsule temperature control includes capsule primary and backup temperatures, control set point, control mode (manual, automatic, purge), and selection of the control TC input signal. The latter provides the process feedback to the control configuration. The output from the temperature control configuration is the control signal for the helium and neon mass flow controllers.

Since the TC temperature is essential for capsule temperature control, it is important that TC readings correctly represent the capsule thermal condition. However, in many cases, due to harsh operating conditions in the irradiation environment, a significant fraction of thermocouples in capsules may deteriorate and fail during the long duration of fuel testing, The three statistical methods discussed in Section 3 help identify early indication of TC malfunction such as drift or virtual junction. Furthermore, the capability of the statistical tools can be augmented by making use of numerical data from physics-based simulations that are run on a daily basis and stored in the NDMAS [9]. These data include the time-average peak fuel temperature and time-average, volume- average fuel temperature, which also are used as the test target quantities. 
Most notably, correlation analysis performed for the simulation-estimated fuel temperatures and the TC readings reveals a strong correlation. Since the gas mixture is adjusted only when the reactor power is at steady state (or at full power), the simulated fuel temperatures and TC readings during that time only are selected for analysis. Table 2 presents the correlation coefficients between the capsule average and peak fuel temperatures and TCs readings in AGR-1 capsule \#6. As expected, the correlation coefficients are high for the calculated capsule average fuel temperature (from 0.8949 for $\mathrm{TC} 2$ to 0.9614 for $\mathrm{TC} 1$ ) and slightly lower for the calculated peak fuel temperature (from 0.8772 for TC2 to 0.9569 for TC1). Overall, the correlation coefficients are high, allowing the linear regression function (as in Eq. 4) be established for each ATR fuel cycle and used to estimate the actual fuel temperature from the TC reading or vice versa.

Table 2: Correlation coefficients between the calculated capsule average fuel temperature, calculated peak fuel temperature and the TCs readings in AGR-1 capsule \#6.

\begin{tabular}{c|cccccc}
\hline & $T C_{-} 1$ & $T C_{-} 2$ & $T C_{-} 3$ & $T C_{-} 4$ & $T C_{-} 5$ & $\begin{array}{c}\text { Peak Fuel } \\
\text { Temperature }\end{array}$ \\
\hline $\begin{array}{c}\text { Average Fuel } \\
\text { Temperature } \\
\begin{array}{c}\text { Peak Fuel } \\
\text { Temperature }\end{array}\end{array}$ & 0.9614 & 0.8949 & 0.9491 & 0.9509 & 0.9332 & 0.9978 \\
\hline
\end{tabular}

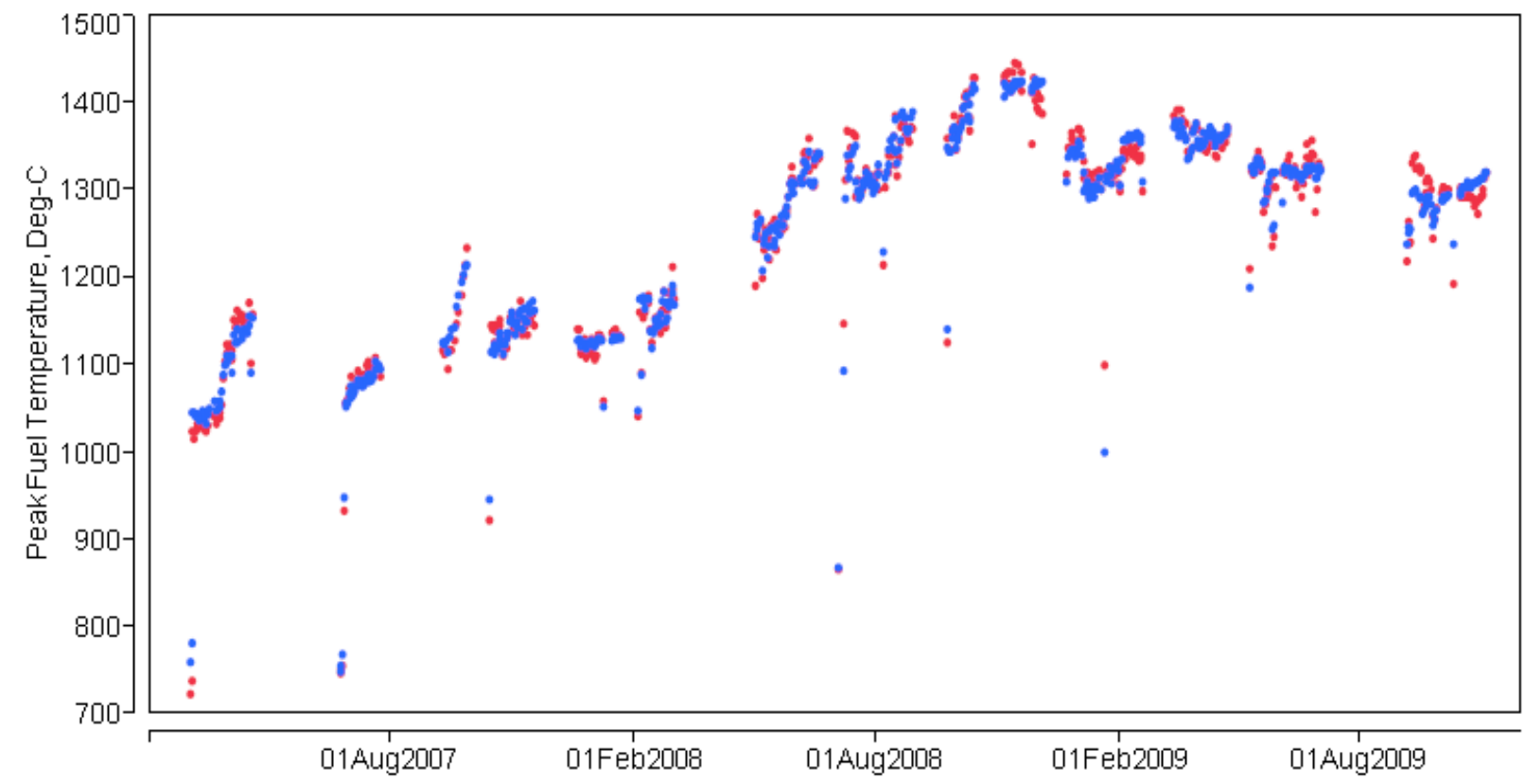

Fig. 11: Peak fuel temperatures in AGR-1 capsule \#6: regression estimated (blue dots) and simulated (red dots).

Figure 11 depicts the simulated (red dots) and the regression-based (blue dots) estimates of the peak fuel temperature in capsule \#6 as linear functions of TC1 constructed for each ATR fuel cycle. Their close fit demonstrates that the target quantity of the peak fuel temperature can be evaluated with high confidence from the 
control TC readings. The same relationship can also be used to control the fuel temperature by setting the control TC input signal $\left(T_{T C}^{C O N T R O L}\right)$ to the value corresponding to the specified fuel temperature $\left(T_{F U E L}^{T A R G E T}\right.$ - either peak fuel temperature or capsule average fuel temperature). The high correlation coefficient between the capsule average and peak fuel temperature $(\mathrm{r}=0.9978)$ also suggests that it suffices to use one type of fuel temperature to control, since the other could be estimated from the controlled quantity.

The procedure proposed for controlling the AGR experiment is as follows:

i. Construct a regression model (estimate the regression coefficients $a$ and $b$ ) for the control TC readings as a function of the calculated fuel temperatures $T_{F U E L}^{C A L C}$ based on available results from daily neutronic and thermal simulations :

$$
T_{T C}^{M E A S}=a T_{F U E L}^{C A L C}+b
$$

ii. Substitute the target fuel temperature $T_{F U E L}^{T A R G E T}$ into $T_{F U E L}^{C A L C}$ in Eq. (5) to estimate the control TC input signal $T_{T C}^{C O N T R O L}$ needed for control set point in the capsule temperature control system.

iii. Periodically update the regression coefficients $a$ and $b$ of Eq. (5) based on new simulated fuel temperatures and TC readings as the experiment progresses, to reflect possible changes in their regression relationship.

Thus, given the assumption about linear heat transfer in the AGR fuel and graphite domain, the experiment control can be achieved by making use of the readings from potential deteriorated TCs without having to explicitly characterize the degree of drifting or a bias in the TC readings.

The above procedure can be extended to use readings from functional adjacent TCs $T_{T C, A D J}^{M E A S}$ in the proximity of a deteriorated or failed TC, i.e. using $T_{T C, A D J}^{M E A S}$ instead of $T_{F U E L}^{C A L C}$ in Eq. (5). The process helps "recover" the failed TC by using its correlation with the adjacent TCs established prior to the failure occurrence.

Remarkably, experience from analysis of AGR-1 test data suggests that during the long duration of fuel testing, several to all thermocouples in individual capsules may fail, leaving the thermal conditions of fuel compacts in such capsules practically unmonitored. Yet, as both the global conditions, i.e. ATR operating parameters (lobe power, shim cylinder positions), and the local conditions i.e. fuel/graphite conditions in the capsule change, the target quantity (e.g. maximum or average fuel temperatures) also vary. It is therefore highly valuable for the test program that the target quantity is maintained within the desired range. Using the algorithms of regression analysis and correlation analysis, and data from functioning thermocouples in the same or neighboring capsules, the missing control data (provided by the now-failed thermocouple) can be evaluated. Such a fill-in, although subject to uncertainties, is instrumental to retain a critical control over the testing conditions in an otherwise unmonitored capsule.

The above-proposed experimental control procedure, along with the statistical analysis techniques implemented in NDMAS, will be used to support new experiments in the AGR series. 


\section{CONCLUDING REMARKS}

Experimental data, particularly data from nuclear fuel performance tests, play an essential role in the design, safety analysis and licensing of nuclear reactors. Notably, highly valuable data on nuclear fuel performance tests are hard to produce and challenging to interpret. On the one hand, it is critical that the test conditions are effectively maintained during the test and accurately characterized to ensure the proper use of the test data in fuel design and safety analysis. On the other hand, even several decades from now, the experimental data obtained in today's tests may remain valuable for the assessment of models and codes developed to predict nuclear fuel performance that support fuel and plant licensing. As more advanced models and high-fidelity simulation methods become available in the future, their utility is expected to be even more sensitive to the knowledge about quality of data used for model validation and uncertainty quantification. For example, it is important that potentially misleading and deteriorated data, i.e., from partially failed (drifted, conjunct) thermocouples, be accordingly identified. The techniques and tools developed in NDMAS support this data qualification objective.

This paper describes the basics and implementation of three statistical analysis methods to support data qualification functions in the NGNP Data Management and Analysis System (NDMAS). Performance of the intended functions was evaluated against the AGR-1 test data, showing the methods capabilities for providing early warning of thermocouple failure modes, e.g. virtual junction and drift. Used together, these techniques become a powerful instrument to improve the quality of the test program.

The AGR simulation results collected in the NDMAS can be very useful in aiding the experimental data qualification, especially increasing the confidence in delineating failures of the measuring instruments (thermocouples) from physical mechanisms that may have shifted the system thermal response. Given a high rate of thermocouple failure under harsh irradiation and thermal conditions in AGR, it may be beneficial to utilize the temperature prediction results from the daily AGR power/thermal simulations to provide early detection of changes (drifting) or failure of thermocouple and support a more effective test control procedure. Thus, it is appealing that the statistical methods developed for test data processing discussed in Section 3 not only can be used for post-test data qualification but also to increase the test quality via regulation of control parameters in the active experiment, including filling-in the missing control data using the maximum likelihood principle.

It is noted that nuclear fuel performance involves complex physical mechanisms, e.g. fissile depletion, graphite and fuel shrinkage, and properties (conductivity, density) change, for which we lack the knowledge and capability to accurately assess the impact of modeling assumptions about these processes under AGR conditions. This greatly complicates the task to separate the contribution from experimentation and simulation to an off-trend

observation. Thus, the combined use of test data and simulation results requires a systematic approach to uncertainty quantification of both experimental measurements on one side, and model and numerical solutions on the other side.

\section{ACKNOWLEDGEMENT}

The authors would like to thank Cindy Gentillon, Mike Abbott, and Larry Hull, all of the Idaho National Laboratory (INL) for their supports and comments on the manuscript. This work is supported by NGNP VHTR R\&D program at INL under the US Department of Energy contract DE-AC07-05ID14517.

\section{REFERENCES}

[1] J. Einerson, Statistical Methods Handbook for Advanced Gas Reactor Fuel Materials, INL/EXT-05-00349, Idaho National Laboratory, (2005). 
[2] INL, Very High Temperature Reactor Program Data Management and Analysis Plan, INL/PLN-2709, Idaho National Laboratory, (2009).

[3] C. Gentillon, M. Abbott, L. Hull, B. Pham, M. Plummer, NGNP Data Management and Analysis System Modeling Capabilities, INL/EXT-09-16327, Idaho National Laboratory, (2009).

[4] J.T. Maki, AGR-1 Irradiation Experiment Test Plan, INL/EXT-05-00593, Idaho National Laboratory, Rev 2, (2007).

[5] D. Petti, R. Hobbins, J. Kendall, and J. Saurwein, Technical Program Plan for the Advanced Gas Reactor Fuel Development and Qualification Program, INL/EXT-05-00465, Idaho National Laboratory, Rev. 2, (2008).

[6] INL, Temperature Control and Off Gas Monitoring Systems for Advanced Gas Reactor Experiment AGR-1, INL/TFR-248, Rev. 3, Idaho National Laboratory, (2009).

[7] M.L. Abbott, L. Hull, B. Pham, and M.A. Plummer, AGR-1 Data Qualification Report, INL/EXT-10-17943, Idaho National Laboratory, (2010).

[8] J.T. Maki, AGR-1 As-Run Analysis Status For FY-07, INL/EXT-07-13630, (2007).

[9] M. Pope, AGR-1 Irradiation Test Final As-Run Report, INL/EXT-10-18097, Idaho National Laboratory, (2010).

[10] ASME, Quality Assurance Requirements for Nuclear Facility Applications, Nuclear Quality Assurance (NQA1), ASME International, New York, NY, (2000).

[11] INL, Very High Temperature Gas Reactor Technology Development Office Quality Assurance Program Plan, INL/PLN-2690, Rev 3, (2009).

[12] INL, FY 2008 Advanced Test Reactor National Scientific User Facility Users' Guide, INL/EXT-07-13577, 38 $\mathrm{p},(2008)$.

[13] SAS, SAS Enterprise Business Intelligence Server, SAS Institute Inc., Cary, NC, (2007).

[14] A.J. Duncan, Quality Control and Industrial Statistics, Third Ed., Richard D. Irwin, Inc., Homewood, Illinois, 1965.

[15] StatSoft Inc., Electronic Statistics Textbook. Tulsa, OK: StatSoft. WEB: http://www.statsoft.com/textbook/, April 20, 2010.

[16] G.W. Snedecor, W.G. Cochran, Statistical Methods, Seventh Ed., Iowa State University Press Ames, Iowa, 1980.

[17] J. Neter, W. Wasserman, Applied Linear Statistical Models, Richard D. Irwin, Inc., Homewood, Illinois, 1974.

[18] B. Ostle, R. Mensing, Statistics in Research, Third Ed., Iowa State University Press Ames, Iowa, 1975.

[19] N. Draper, H. Smith, Applied Regression Analysis, John Wiley \& Sons, Inc., New York, 1966.

[20] SAS Institute Inc., SAS OnlineDoc ${ }^{\circledR}$ 9.1.3. Cary, NC: SAS Institute Inc, 2008. 